\title{
High refuge availability on coral reefs increases the vulnerability of reef-associated predators to overexploitation
}

\author{
Alice Rogers, ${ }^{1,4}$ Julia L. Blanchard, ${ }^{2}$ Steven P. Newman, ${ }^{3}$ Charlie S. Dryden, ${ }^{3}$ And Peter J. Mumby ${ }^{1}$ \\ ${ }^{1}$ Marine Spatial Ecology Lab and Australian Research Council Centre of Excellence for Coral Reef Studies, School of Biological \\ Sciences, The University of Queensland, Goddard Building, Brisbane, Queensland 4072 Australia \\ ${ }^{2}$ Institute of Marine and Antarctic Studies and Centre for Marine Socioecology, University of Tasmania, 20 Castray Esplanade, \\ Hobart, Tasmania 7004 Australia \\ ${ }^{3}$ School of Marine Science and Technology, Newcastle University, Newcastle NE1 7RU UK
}

\begin{abstract}
Refuge availability and fishing alter predator-prey interactions on coral reefs, but our understanding of how they interact to drive food web dynamics, community structure and vulnerability of different trophic groups is unclear. Here, we apply a size-based ecosystem model of coral reefs, parameterized with empirical measures of structural complexity, to predict fish biomass, productivity and community structure in reef ecosystems under a broad range of refuge availability and fishing regimes. In unfished ecosystems, the expected positive correlation between reef structural complexity and biomass emerges, but a non-linear effect of predation refuges is observed for the productivity of predatory fish. Reefs with intermediate complexity have the highest predator productivity, but when refuge availability is high and prey are less available, predator growth rates decrease, with significant implications for fisheries. Specifically, as fishing intensity increases, predators in habitats with high refuge availability exhibit vulnerability to overexploitation, resulting in communities dominated by herbivores. Our study reveals mechanisms for threshold dynamics in predators living in complex habitats and elucidates how predators can be food-limited when most of their prey are able to hide. We also highlight the importance of nutrient recycling via the detrital pathway, to support high predator biomasses on coral reefs.
\end{abstract}

Key words: coral reefs; habitat complexity; overfishing; predation refuges; predator-prey interactions; productivity.

\section{INTRODUCTION}

Predator-prey interactions are fundamental drivers of the structure and functioning of natural ecosystems (reviewed in Sih et al. 1985, Barbosa and Castellanos 2005). Food web models are commonly used to capture trophic interactions and explore how they determine community dynamics such as biodiversity, ecosystem stability, carrying capacities and productivity (Hixon and Menge 1991, Hixon and Beets 1993, Chase 1999, Blanchard et al. 2010). Physical refuges allow prey to escape predation, mediating predator-prey interactions and altering food web dynamics. Refuges have been shown to have positive effects on prey, including the prevention of extinction (McNair 1986), some negative effects on predators (González-Olivares and Ramos-Jiliberto 2003), and in general promote stability in predator-prey oscillations (McNair 1986, Sih 1987). Most of these studies used simple multi-species models and considered the binary influence of having some, vs. no predation refuges. In contrast, few food webs have captured how gradients of refuge availability influence trophic dynamics and community structure. Furthermore, few have captured the

Manuscript received 7 July 2017; revised 16 October 2017; accepted 24 October 2017. Corresponding Editor: Richard B. Aronson.

${ }^{4}$ E-mail: a.rogers2@uq.edu.au changes in vulnerability, feeding rates and growth rates that occur throughout the lives of organisms (Werner and Gilliam 1984, Chase 1999), the mediation of refuge use through competition and predation risk (Chase et al. 2002, Almany 2004), and the fact that most predators are themselves prey at some stage in their lives. Here we aim to incorporate these realistic dynamics and explore how changes in prey availability due to refuge availability affect predator-prey interactions and community dynamics. We focus in particular on the influence of refuges on the productivity of predator populations, using this ecological process to gain insight into the implications of refuge availability for ecosystem services. Coral reefs provide the ideal model system for our study, and reef fisheries productivity the ecosystem service for discussion.

Owing to a diversity of carbonate building organisms, healthy coral reefs have complex three-dimensional habitats, with cracks, crevices and holes that act as predation refuges and mediate predator-prey interactions (Hixon and Menge 1991). The abundance and size-structure of reef refuges can vary dramatically in space and time owing to differences in coral cover, diversity and underlying geomorphology. In the face of environmental and anthropogenic stressors many coral reefs are becoming flatter, resulting in changes to refuge availability (Alvarez-Filip et al. 2009, Graham and Nash 2012). 
Also, due to exploitation and other external sources of mortality, predator and prey abundances are inherently variable on coral reefs, affecting competition rates and predation risk and therefore mediating the effects of refuge availability on community dynamics.

Empirical studies show that structurally complex coral reefs with many refuges support higher densities (Friedlander et al. 2003, Gratwicke and Speight 2005), higher biomass (Grigg 1994, Friedlander et al. 2007, Wilson et al. 2012), greater species richness (Luckhurst and Luckhurst 1978, Newman et al. 2015) and longer food chains (Alvarez-Filip et al. 2011) of reef fish than low complexity reefs. Through the development of a sizebased ecosystem model that allowed for ontogenic changes in vulnerability and feeding, we previously explored the theoretical effects of predation refuges on reef fisheries productivity (Rogers et al. 2014). We showed that, with all else being equal, the provision of refuges could increase the productivity of a reef fish assemblage. We conducted our study on reefs protected from fishing and as such our results were relevant to intact food webs with high competition and predation risk. In reality however, the majority of the worlds' reefs are exploited to a greater or lesser extent (Newton et al. 2007, MacNeil et al. 2015), and through the removal of large individuals, fishing also affects predator-prey interactions. Fishing alters the abundance and size structure of the community (Dulvy et al. 2004b, Wilson et al. 2010) and changes the balance between predation and survival in different parts of the food web. Quantifying the relative importance of refuge availability and fishing on community dynamics is challenging because it is difficult to disentangle the respective effects (Wilson et al. 2012). A community altered by exploitation may respond differently to changes in refuge availability than a community with an intact food web.

Here, we ask how refuge availability and fishing mortality interact to mediate predator-prey interactions and determine coral reef community structure and trophic dynamics. To do so we adapt our original size-based ecosystem model of coral reefs, which captures key trophic dynamics including size-based predation, piscivory, invertivory, herbivory and detrital recycling, as well as a density-dependent refuge effect. We parameterize it with empirical data on the abundance and sizestructure of refuges from reefs spanning a broad range of habitat quality, and explore model dynamics in systems subjected to increasing levels of exploitation. Model predictions allow us to address three key questions:

1. How does refuge availability mediate predator-prey interactions and determine the abundance and productivity of predatory and herbivorous trophic groups?

2. Is biomass a good proxy for productivity in communities living in complex habitats with variable refuge availability?
3. How does refuge availability interact with fishing pressure to drive predator productivity, and what are the implications for coral reef fisheries?

\section{Methods}

\section{Refuge abundance and size structure on coral reefs of varying habitat quality}

Structural complexity on coral reefs is generally quantified on a relative scale from high to low. Common methods of estimation include the calculation of rugosity indices (Risk 1972), classification on a five-point scale (Wilson et al. 2008, Alvarez-Filip et al. 2011), and maximum vertical relief (Harborne et al. 2012). Although these methods allow for comparisons among reefs, they do not enable explicit consideration of the effects of refuge availability on predator-prey interactions. Quantifying the abundance and sizes of crevices on reefs is labor-intensive, but provides a valuable measure of refuge availability for reef fish of different sizes and stages of development. Studies that have obtained such measures on both natural and artificial reef systems have shown that crevice abundance and size correlate with fish abundance and size structure (Hixon and Beets 1989, Friedlander and Parrish 1998).

We quantified the abundance and size distribution of crevices on reefs spanning a range of habitat quality on the Indonesian island of Selayar in South Sulawesi, close to the global center of marine shore fish biodiversity (Carpenter and Springer 2005). Those reefs with the highest complexity had relatively high $(55-60 \%)$ and diverse coral cover, whilst the worst were rubble fields resulting from destructive bomb fishing. Sites were chosen not for their similarity in environmental conditions, but rather for their broad range of natural variation in habitat structural complexity and refuge distribution. Appendix S1: Fig. S1 shows the location, and details of each site.

Refuges were counted in $5 \mathrm{~cm}$ size classes, from 5 to $50 \mathrm{~cm}$, on four replicate $10 \mathrm{~m} \times 1 \mathrm{~m}$ transects per site. Size classes were assigned with the use of fish models, designed to captured accurate fish body depths, relative to length, based on common wrasse and parrotfish body shapes. Refuges were defined as any crevice within the reef framework that offered physical protection such that the fish model was hidden from view and sheltered on at least two sides. Crevices included spaces within corals, between corals of different growth forms and underneath various overhanging structures. Large overhangs, and other crevices in excess of $50 \mathrm{~cm}$ in length were not quantified because the model did not represent fish larger than this body size. In addition, the planar area of branching corals was quantified in classes of fine branch space $(1-2.5 \mathrm{~cm})$ and medium branch space $(2.5-5 \mathrm{~cm})$. Using the image analysis tool, imageJ we estimated that an average branching coral consisted of two-thirds branches and one-third branch space, and used this to convert branching coral area to refuge density by dividing the total branch space 
area by the maximum branch space. This method allowed for a rough estimation of the density of small fish that branching corals could protect. Refuge density (number of holes per $\mathrm{m}^{2}$ ) per size class, per site was calculated by taking averages from the four replicate transects.

\section{Modeling the influence of refuge availability under increasing fishing pressure}

To explore the relative influence of refuge availability and exploitation on the abundance, productivity and community structure of reef fish assemblages, and address our three aims, we extended our original model (Rogers et al. 2014) to incorporate benthic primary production and grazing dynamics explicitly, and to allow for density-dependent effects of refuges on predation vulnerability. The model describes three size-structured trophic groups: predatory fish, herbivorous fish and invertebrates. Predatory fish feed in a size-dependent manner on smaller predators, herbivores and invertebrates. The smallest predators feed on a constant, non-dynamic supply of planktonic primary production. Herbivorous fish feed on algal turfs, which flux into the system through annual production, and invertebrates feed on detritus, which fluxes into the system as a result of death and defecation from each of the three trophic groups, and from the planktonic primary production spectra (phytodetritus). Through the strongly coupled detrital pathway (Hatcher 1988, Alongi 1989), nutrients are recycled into the food web, thus assuming a relatively closed system. The model relates only to reef associated fish species below a maximum body size of $\sim 50 \mathrm{~cm}$, because the foraging behaviour and energetics of larger roaming predators are not well captured by the assumption of a closed system. Model equations and more detailed model descriptions can be found in Appendix S1: Table S1.

Initial size spectra intercepts of reef fish were set such that the abundances of the smallest size classes were between one and ten per square meter, in line with surveys of reef fish recruits from both the Indo Pacific and Caribbean (Ackerman et al. 2004, Depczynski et al. 2007). The intercept for planktonic primary production was adjusted upwards from the fish intercept to 10 times the density. This roughly accounts for losses associated with energy transfer from plankton to reef fish recruits, as in Woodworth-Jefcoats et al. (2013). Model parameter values and justification can be found in Appendix S1: Table S2.

To incorporate empirical measures of refuge availability, we developed a mechanistic, density-dependent vulnerability function. Reef fish sizes in the food web model were expressed in $\log 10$ body mass increments, so crevice size-densities (based on length) for each reef were assigned as suitable refuges to ranges of fish body mass increments based on average length-weight conversion parameters $(a=0.025, b=3$, Appendix S1: Table S3). At each time step, for each fish body size ( 0.1 increments of $\log 10$ body mass), predation vulnerability was equal to one minus the number of available refuges divided by the numerical density of competitors. This resulted in a proportion of the population in each body size that is outside of a refuge and vulnerable to predation. A lower limit of zero was set for the function to prevent any case allowing for an unrealistic negative vulnerability. Fig. 1 gives examples of the realized vulnerability of different fish body sizes at two reefs with contrasting high and low structural complexity, with no fishing or high degrees of exploitation. Three simplifying assumptions were made; (1) invertebrates are not influenced by refuge availability in the $2.5-50 \mathrm{~cm}$ size range because the majority of reef invertebrates are small, and commonly use reef rubble or algal canopies as habitat (Roff et al. 2013, Kramer et al. 2014), (2) reef fish utilize refuges that most closely match their body size, and (3) competition for refuges occurs only between fish of the same body size. These assumptions are discussed further in the section entitled limitations and future avenues for research. In all model simulations, only parameters relating to the vulnerability function were altered, whilst all others were held constant.

Model simulations were run for $50 \mathrm{yr}$ to equilibrium across a range of fishing intensities that determined competition and predation risk. A range of size-specific relative fishing mortality from $0 \mathrm{yr}^{-1}$, to $1 \mathrm{yr}^{-1}$ was applied to align with scenarios of intact food webs to depleted assemblages (Blanchard et al. 2012). Relative fishing mortality is the proportion of the population, at each size that dies as a result of fishing. We assumed a minimum capture size from fishing of approximately $\sim 10-15 \mathrm{~cm}$, because the reef fisheries of Selayar are not regulated by size restrictions, and observations at fish markets identified a significant contribution of small fish to the daily catch (A. Rogers, personal Observation). We also assumed that predators and herbivores were targeted with equal fishing effort, which was consistent with market observations but also allowed for controlled comparisons in the response of each trophic group.

To explore how refuge availability influenced reef fish across a range of exploitation, we generated model predictions of fish biomass and productivity for each scenario. Productivity was defined as the product of growth and abundance, and expressed as a rate in $\mathrm{g} \cdot \mathrm{m}^{-2} \cdot \mathrm{yr}^{-1}$. It reflects the flux of energy into organisms, or the turnover rate, and is an informative measure not only for application to fisheries, but also population recovery following other sources of external mortality. We extracted data on abundance and productivity for predatory and herbivorous fish separately, as well as both fish groups combined. To elucidate implications for reef fisheries, we also explored how total annual yield $\left(\mathrm{g} / \mathrm{m}^{2}\right)$ and catch composition might vary among reefs with different refuge availability and fishing pressure.

To visualize and test for associations between habitat structural complexity and fish biomass, productivity and community structure, we present our detailed refuge sizedistribution data in a single descriptor; the total refuge density per site (number of holes or branch spaces per 

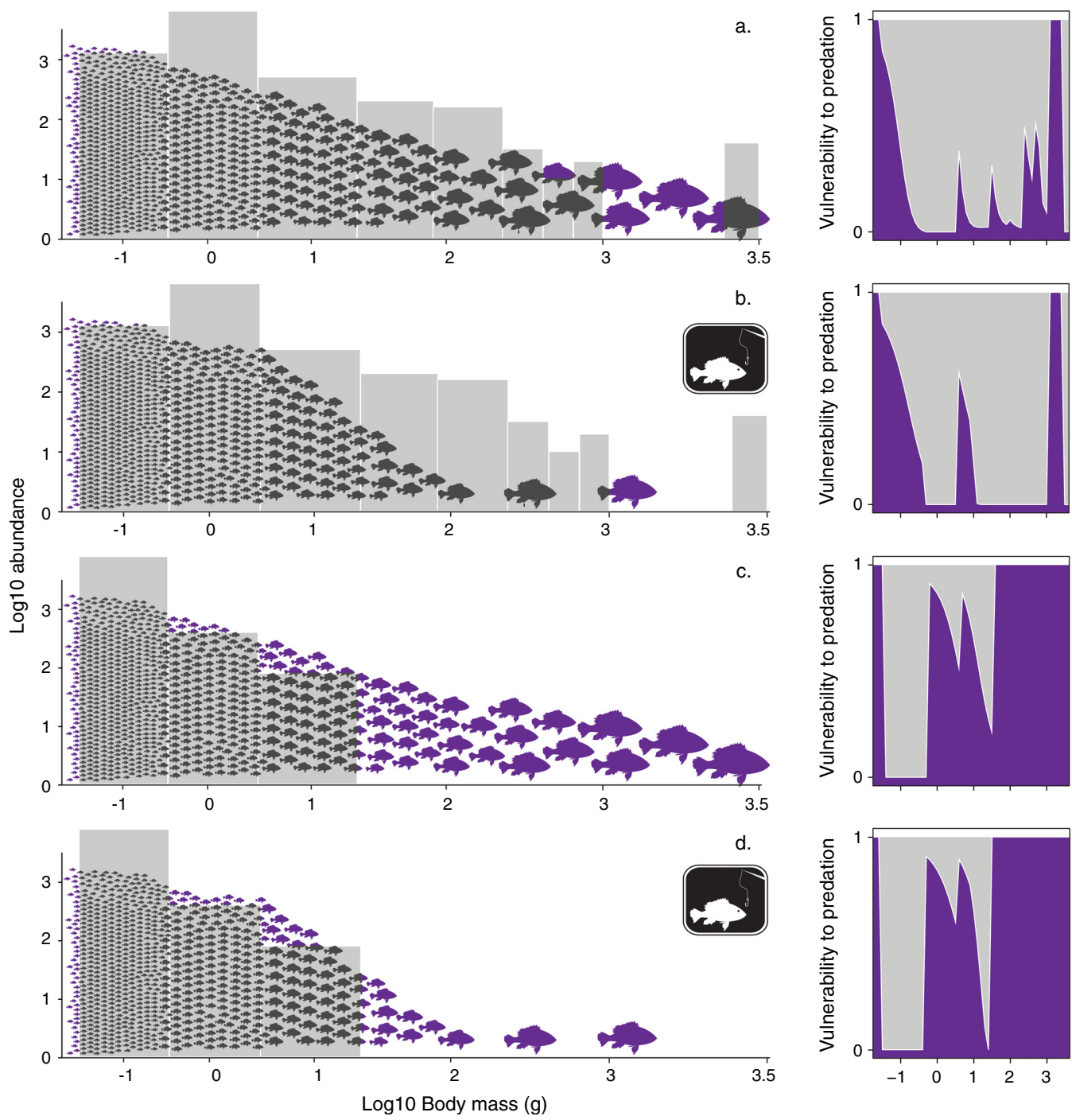

FIG. 1. Habitat complexity affects vulnerability. Examples of how empirically measured crevice size distributions (grey) relate to fish size spectra (purple) to generate a unique vulnerability function (second column) for each reef, which determines what proportion of fish in each body size is vulnerable to predation. Panels (a) and (b) show a complex site with many refuges, whilst panels (c) and (d) show a site with few. Panels (b) and (d) show how the size-based vulnerability function changes in response to depleted fish densities in the face of heavy exploitation.

$\mathrm{m}^{2}$ ). This representation serves to simplify the visualization of key trends. All refuge size distribution data is retained within the model simulations. We also included in our scenarios a theoretical reference reef without refuges.

\section{Model validation}

To validate the predictions of the model in the absence of exploitation, we needed an independent dataset from a location with minimal fishing, but comparable empirical measurements of crevice abundance and diversity. In the absence of such for Selayar and elsewhere in Indonesia, we explored data from the relatively un-fished reefs of Bonaire in the southern Caribbean. Although differences exist in the diversity and functioning of Caribbean and Pacific reefs, data for Bonaire indicated biomasses of both predatory and herbivorous fish that fell within estimated ranges for protected reefs in the South East Asia Pacific and West Indian Ocean (McClanahan et al. 2011, MacNeil et al. 2015). Furthermore, the quantification of refuge abundance and size was carried out using comparable methods in both locations.

Predicted biomasses, size-spectra and growth rates of predatory and herbivorous fishes from equilibrium models without fishing pressure were compared to fish survey data and Caribbean species growth rate data (FishBase) to assess model efficacy. The only differences between the model inputs for Selayar and Bonaire were the refuge size-density input parameters. The fishing mortality rates were also set to zero for Bonaire. 


\section{RESULTS}

\section{Model validation}

Our model predictions using empirical crevice abundance and diversity data from relatively unexploited reefs in Bonaire, match well with corresponding fish abundance and size-structure data from the same study (Fig. 2). Predicted biomasses of predatory fish were good for most reefs, with some model over-estimation at sites that had the lowest biomass, and under-estimation at those that had the highest (Fig. 2). Likely explanations include; (1) some fishing pressure at low biomass sites that is not accounted for in models and (2) the inclusion of transient, schooling, or specialist predators in surveys from high biomass sites, whose behaviors and abundance may not be well captured by our models. Predator dynamics in the model are also complicated because they depend not only on refuge availability that is empirically derived, but also invertebrate dynamics and detrital pathways for which data and parameterizations are more uncertain.

The predicted biomasses of herbivorous fish match data estimates well, and appear to capture variation between sites effectively. This is encouraging because, unlike predator dynamics, herbivore dynamics are driven primarily by refuge availability. This indicates that our models are doing a good job of capturing the effect of empirically derived refuge size structure on abundance and biomass. It also suggests that our global input of benthic production is appropriate to support observed herbivore population biomass. Comparing the predicted and observed growth rates of reef fish from the Caribbean we see that the model does a reasonable job for both predators and herbivores (Fig. 2b). Note that modeled growth rates of larger predators vary significantly between body sizes and reef sites. This is due to differences in the availability of their prey, driven by variability in the abundance and size structure of refuges at different locations. The same patterns do not exist for herbivores because their food resource does not change in response to predation refuges.

\section{The influence of refuge availability on predator and herbivore abundance and productivity}

Predicted total fish biomass, in the absence of fishing, varied significantly among sites, with the "best" site having around 3-fold higher biomass $\left(117 \mathrm{~g} / \mathrm{m}^{2}\right)$ than the worst $\left(35 \mathrm{~g} / \mathrm{m}^{2}\right)$. Biomass was positively, but asymptotically correlated with total refuge density (Fig. 3a). When predators and herbivores were considered separately, predators showed a similar pattern, but herbivores showed a more linear response, and more than a 4-fold difference in biomass between the best $\left(34 \mathrm{~g} / \mathrm{m}^{2}\right)$ and worst $\left(8 \mathrm{~g} / \mathrm{m}^{2}\right)$ sites (Fig. 3b).

The total productivity of fish in fisheries-relevant size classes increased initially from sites with low refuge density, but beyond an optimum, intermediate level, it decreased so that reefs with high refuge density were equally or less
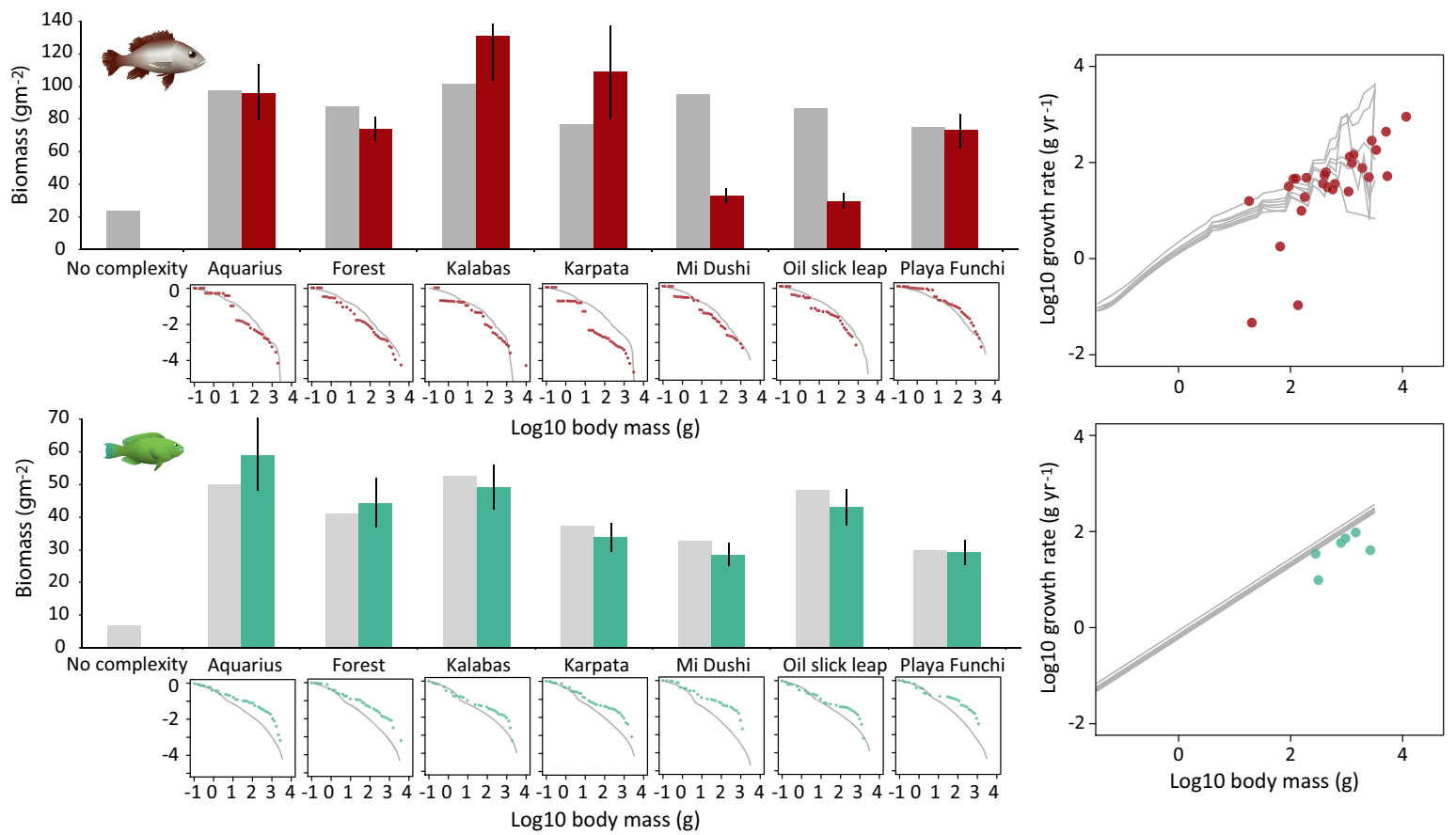

FIG. 2. Comparisons between model predictions (grey) and survey data (colors; red $=$ predators, green $=$ herbivores) relating to seven coral reef sites with low fishing pressure in Bonaire. (a) Bar charts show comparisons of biomass, with associated scatter plots comparing fish size structure as captured by the pareto distribution. (b) Growth rates of common Caribbean species. 

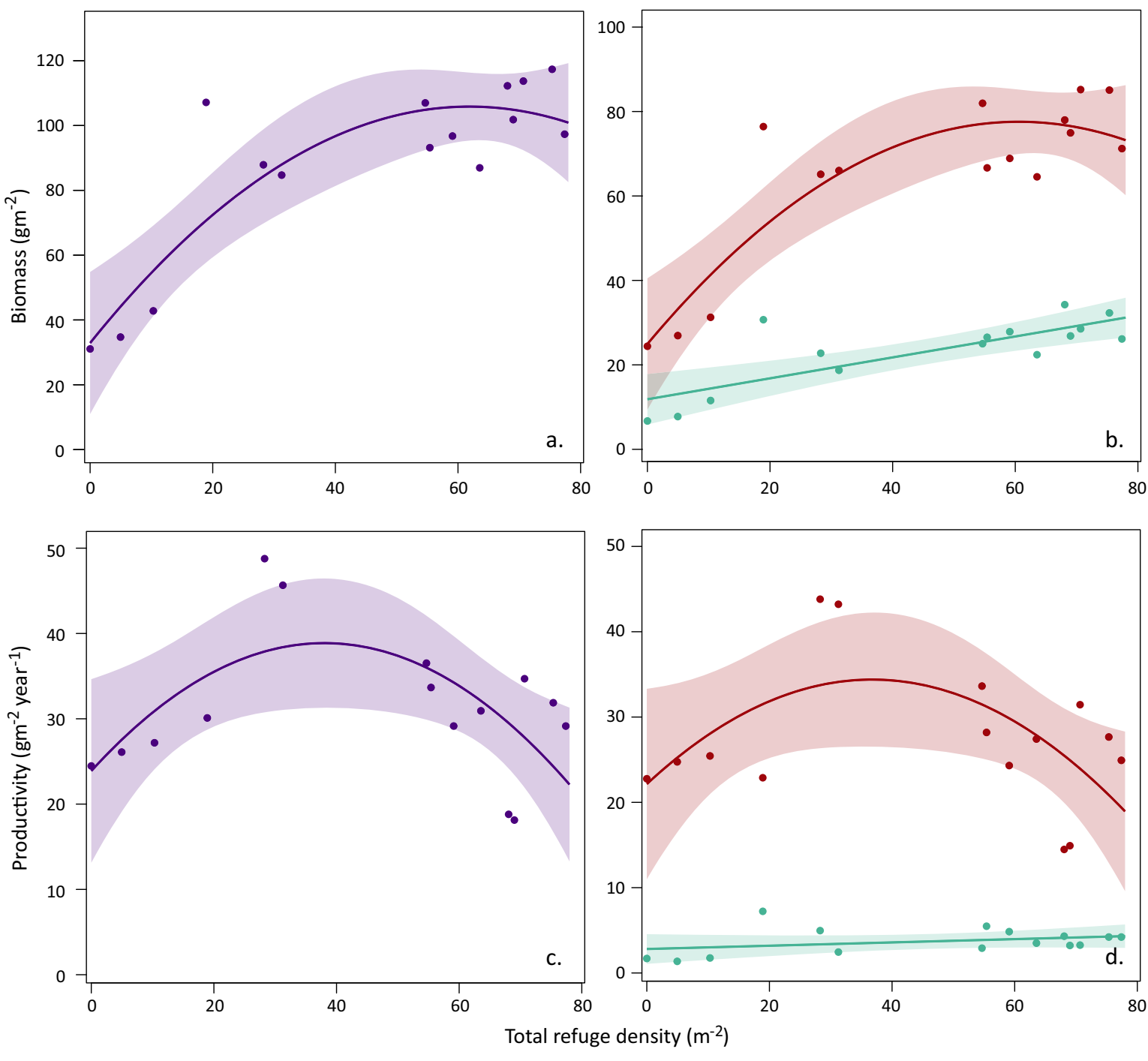

FIG. 3. Relationships between modeled fish biomass (a and b), modeled fisheries productivity (c and d) and observed coral reef structural complexity (represented by refuge density) at each site in Selayar. Purple panels represent patterns for the whole fish assemblage, whereas red and green panels show the patterns for predators and herbivores respectively. Points represent theoretical model predictions relating to each reef site and for illustrative purposes, lines are fitted quadratic or linear curves, with shading showing $95 \%$ confidence intervals for the fits.

productive (Fig. 3c). The hump-shaped pattern in total productivity was driven by the response of predatory fish, whilst herbivore production was simply positively and linearly correlated with refuge density (Fig. 3d).

\section{Biomass as a proxy for productivity in communities with predation refuges}

Comparing the responses of fish biomass and productivity to predation refuge availability, we see a positive correlation for herbivorous species, with biomass and productivity both increasing with increasing refuge availability. For predators however, there is a more complex interaction. At low to medium levels of refuge availability, the positive correlation between biomass, productivity and refuge availability persists, but there is a decoupling of the relationship when refuge density is high. Beyond an intermediate level of refuges, the productivity of predators becomes negatively correlated with refuge density, while the biomass remains positively correlated. The pattern reflects reduced prey availability for larger predators, resulting in a reduction in growth rates in habitats with high refuge availability. As a result, biomass is not a reliable proxy for productivity in predators living in habitats with high refuge availability.

\section{Refuges, fishing, and the implications for coral reef fisheries}

Differences in refuge availability affect emergent predictions of community structure and fishery catches 
across a range of fishing pressures. At low fishing pressure, coral reefs with high refuge availability yield higher catches than those lacking in refuges, generally by two to three-fold. For example, at a fishing mortality rate of 0.1 , a low complexity reef was predicted to yield a catch of around $27 \mathrm{~g} \cdot \mathrm{m}^{-2} \cdot \mathrm{yr}^{-1}$, whereas other reefs with intact habitats yielded between 60 and $90 \mathrm{~g} \cdot \mathrm{m}^{-2} \cdot \mathrm{yr}^{-1}$ (Fig. 4a). Comparing scenarios with increasing intensities of fishing pressure, we found that catch from habitats with many predation refuges was higher at intermediate fishing pressure, but lower when fishing mortality was further increased. Conversely, catch in sites with few refuges showed a more consistent increase with increasing fishing pressure (Fig. $4 \mathrm{a}$, fishing mortality $\sim 0.5-1$ ). The fishing pressure at which a particular reef gave its highest yield (the optimum fishing pressure) was negatively correlated with refuge density (Fig. 4b). This suggests that reefs with high refuge availability have a lower optimal fishing pressure, and are more sensitive to overexploitation. Examining the proportional depletion of predators in response to fishing and refuge density, we see that the declines in total catch above a threshold of fishing are the result of collapse in the predator population (Fig. 4c). The relationship between refuge availability and the ratio of unexploited to fully exploited predator biomass reveals that even relatively low levels of refuge density infer vulnerability to predator population collapse at high fishing pressure (Fig. 4d).

Examining the composition of catches, we found that herbivores made up a small proportion of the total fish catch in reefs with few predation refuges, regardless of fishing pressure, but a greater proportion on reefs with higher refuge density (Fig. 5a). As fishing pressure was increased on reefs with more refuges, the proportion of
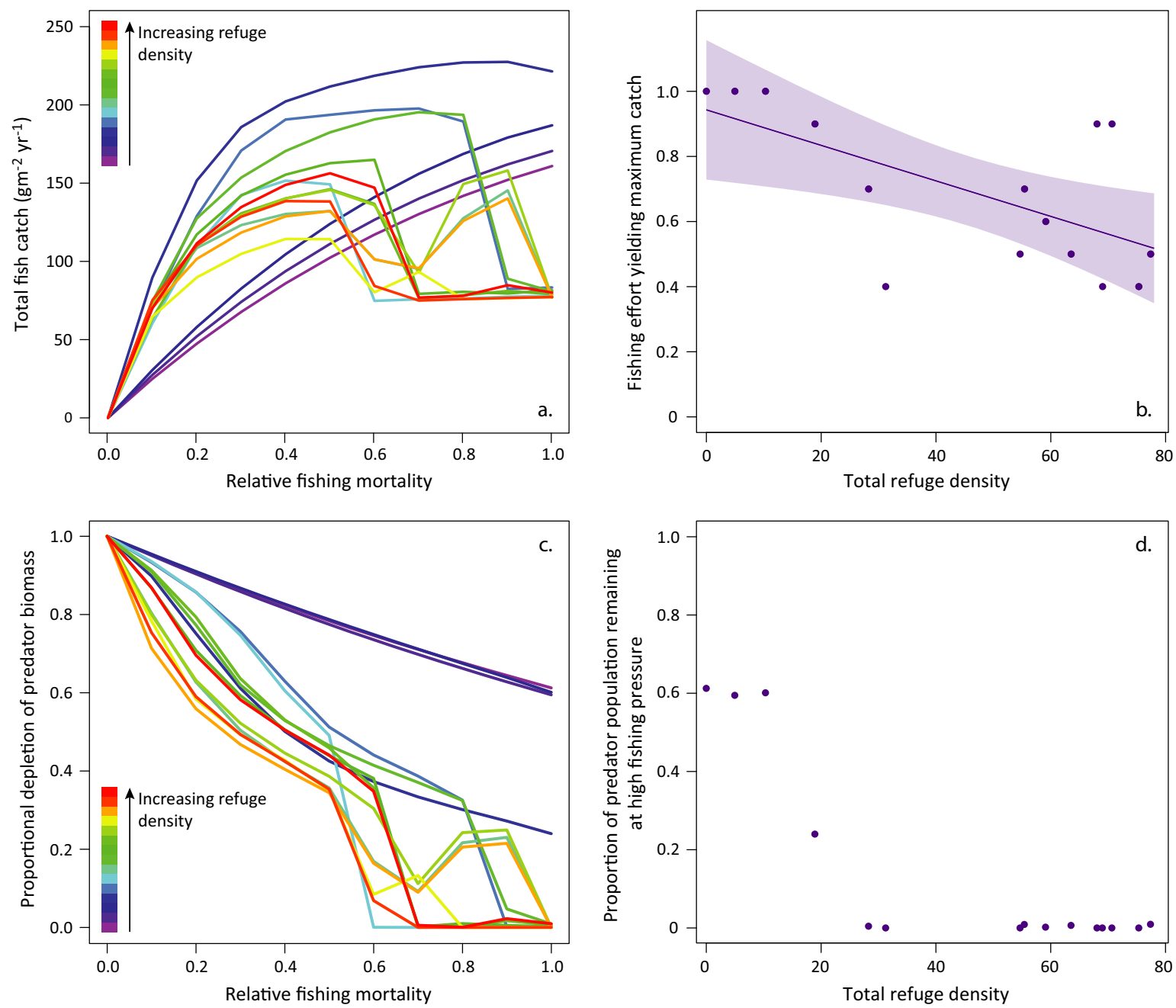

FIG. 4. (a) Predicted total catch in response to relative fishing mortality and coral reef refuge density. (b) Negative relationship between the optimal fishing effort that yields highest catch, and coral reef refuge density. (c) Proportional depletion of predatory fish in response to relative fishing mortality and coral reef refuge density and (d) the proportion of predatory fish that remain in a fully exploited scenario (Relative fishing pressure $=1$ ) in response to coral reef refuge density. 

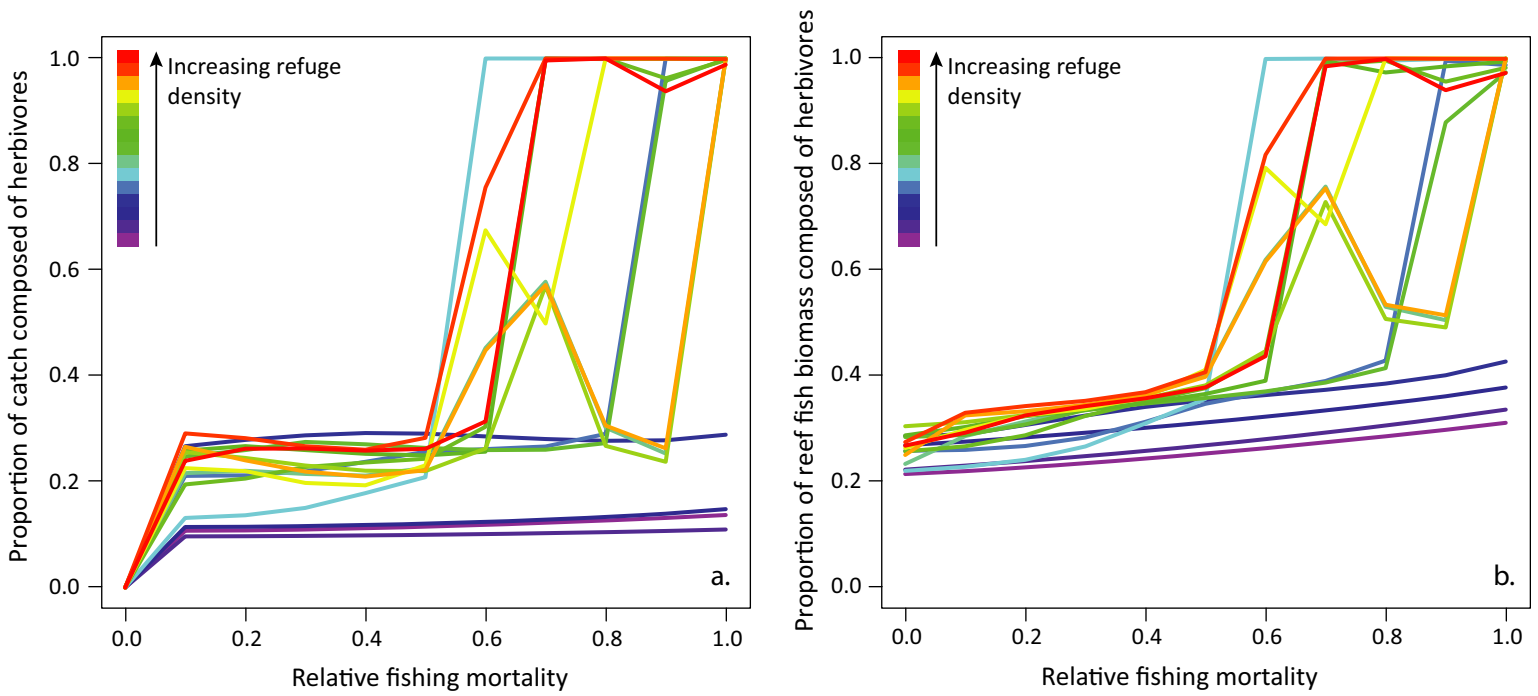

FIG. 5. The relative contribution of herbivores to fish catches (a) and remaining fish biomass (b) in relation to relative fishing mortality and coral reef refuge density.

the catch composed of herbivores increased rapidly beyond a critical threshold (Fig. 5a). The increase coincided with the collapse of the predator population (Fig. 4c), resulting in the dominance of herbivores on the reef (Fig. 5b). An important point to note is that herbivore dominance occurred at lower fishing pressure in sites with higher refuge density, and did not occur at all at sites that had low densities, or no refuges.

Our results pertaining to total catch and catch composition indicate critical thresholds, or tipping points in fishing pressure when refuge availability is high, beyond which predator populations collapse and herbivores become the dominant guild. To elucidate the mechanism of this change we examined the biomass dynamics of predators, herbivores and invertebrates from a representative reef with high refuge density (green line in previous plots) with no fishing, fishing at the observed threshold, and heavy overfishing (Fig. 6). Plots reveal that the collapse of the predator population coincides with oscillations in the invertebrate population. Oscillations are indicative of ecological tipping points (Law et al. 2009, 2012, Plank and Law 2011), and this pattern suggests that predators are reliant on invertebrate prey, whose abundance varies, and is dependent on detrital recycling and the detrital energy pathway.

\section{Discussion}

This study uses a size-based ecosystem model for coral reefs with density-dependent refuges, to explore the relative effects of refuge availability and fishing pressure on reef fish biomass, production and catch. The novel modeling framework allows us to vary only those parameters that correspond to refuge availability and fishing, thus disentangling their relative and confounding influences on predator-prey interactions and ecosystem dynamics. Moreover, due to its size-based nature, and empirically derived refuge function, the model captures the influence
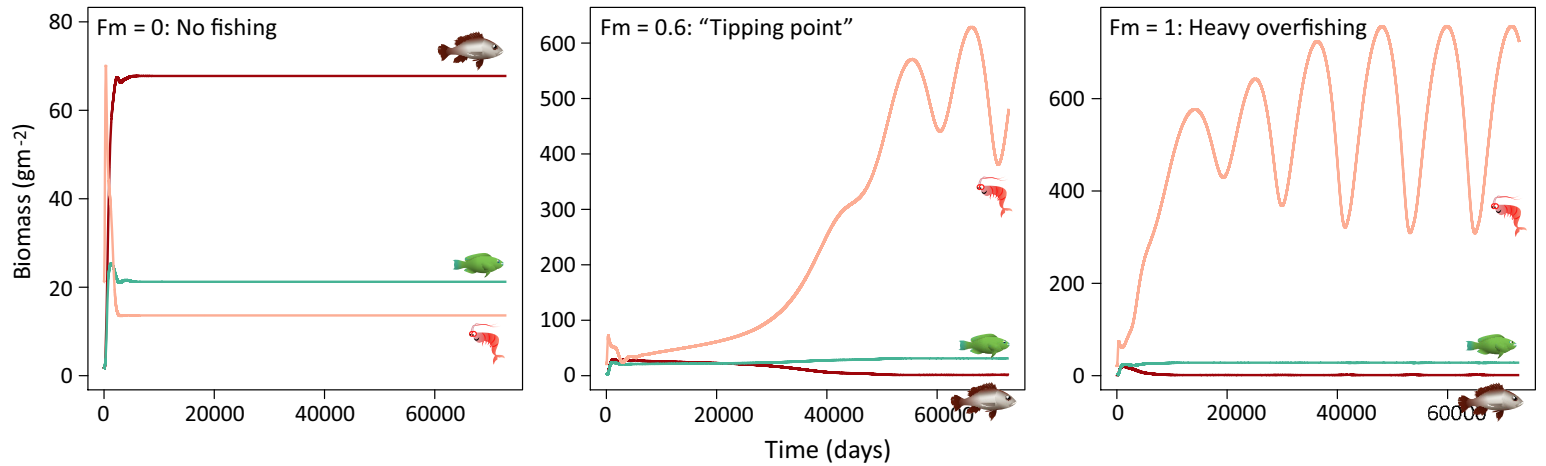

FIG. 6. Example of changes in biomass dynamics of predators, herbivores and invertebrates at a reef site with high refuge availability under increasing fishing pressure. Plots demonstrate emerging instability in invertebrate dynamics in response to fishing, a breakdown of the detrital energy pathway and a collapse of the predatory fish population. 
of real-life habitat complexity on different trophic levels and sizes of fish. In doing so it accounts for changes in vulnerability, competition and resource availability that occur through ontogeny (Almany 2004), and in response to predator abundance.

\section{The influence of refuge availability on predator and herbivore abundance and productivity}

The predicted positive correlation between fish biomass and structural complexity concurs with numerous empirical studies on coral reefs (reviewed in Graham and Nash 2012). It is interesting to note that the relative difference between the worst and best reefs was greater for herbivores, than for predators, suggesting that refuges play a particularly important role in driving herbivore populations in systems with intact food webs. This supports other studies identifying high sensitivity of herbivorous families to lost complexity (Mumby and Wabnitz 2002, Bejarano et al. 2010, Graham and Nash 2012). Here, the patterns were driven by a reduction in predation mortality, but in reality reef structural complexity is likely to provide additional benefits, including nesting, recruitment and foraging sites (Karino and Nakazono 1993, Feary et al. 2007), and for herbivores, possibly greater resource availability (Bozec et al. 2013).

The non-linear relationship we predict between predatory fish production and refuge availability is insightful, and not an attribute that could be detected with observational surveys. The hump-shaped relationship indicates an initial positive effect of refuges on predatory fish production, followed by a negative effect when refuge density is high. Most studies pertaining to habitat complexity on reefs focus on the benefits of structure (i.e. homes and hiding places for vulnerable organisms) and rarely do we consider the implications for predators higher up the food chain, which generally have higher energetic demands. It reasonably follows that if refuges are good for prey, they aren't necessarily good for the predators that eat those prey. Our models capture a reduction in growth in larger, reef-associated predators when their prey are less available, demonstrating how complexity can be both good and bad for this guild. Moreover, we find evidence of a threshold of refuge availability beyond which too much structure can have negative effects on predator productivity. Our previous modeling study detected a similar pattern based on theoretical refuge structure alone (Rogers et al. 2014), but here we show that the threshold falls within the range of natural refuge densities observed on coral reefs. Importantly, the non-linear pattern between productivity and refuge availability was not apparent for herbivores, which exhibited a positive linear response.

\section{Biomass as a proxy for productivity in communities with predation refuges}

A number of key studies have utilized biomass as a proxy for productivity and ecosystem service provision
(Cardinale et al. 2006, terHorst and Munguia 2008, Mora et al. 2011). Biomass is generally easily measured and commonly monitored whereas productivity is a dynamic rate that cannot be readily observed. When we are concerned with exploitation or recovery however, knowing the rate at which individuals are replaced following their removal is valuable. Our study elucidates a decoupling of the correlation between biomass and productivity in predators that live in complex habitats with predation refuges. The pattern is driven by food limitation and reduced growth of predators owing to less available prey. A recent empirical study in Bermuda highlighted the potential for food limitation in a reef associated trumpet fish, Aulostomus maculatus, whose biomass increased 6-fold in response to increased prey resource availability (O'Farrell et al. 2015). Further field studies are needed to confirm trophic limitations in predators in high complexity habitats, and the extent to which limitations may be overcome by specialized foraging behaviors but in the meantime, our findings caution against the conventional wisdom of using biomass as a proxy for productivity in systems with predation refuges.

\section{Refuges, fishing, and the implications for coral reef fisheries}

Discovering that at low fishing pressure, structurally complex reefs support around a 2-3-fold higher catch than reefs with little or no complexity, agrees with previous modeling studies (Rogers et al. 2014), and our general understanding that reefs with a healthier benthos (greater complexity) have higher fisheries productivity (Jennings and Nicholas 1996, Rodwell et al. 2003). However, our prediction that higher refuge densities also imply an increased risk of predator over-exploitation is both novel and concerning. We know that the majority of the worlds' coral reefs show depauperate assemblages of predators, in particular those of the largest body sizes (Jackson et al. 2001, Dulvy et al. 2004a, MacNeil et al. 2015). Preferential targeting is one of the major causes (Pauly 1998), but vulnerability has also been attributed to life history traits such as slow growth and large size at maturity (Jennings et al. 1999, Myers and Worm 2005, Abesamis et al. 2014). This study highlights an additional mechanism for vulnerability in larger reefassociated predators living in habitats with lots of predation refuges.

Our model does not include a stock-recruit relationship, meaning that recruitment rates are constant and independent of adult spawner-stock biomass. As a consequence, modeled populations tend to be less susceptible to collapse. However, the model produces threshold levels of fishing on structurally complex reefs, beyond which predator populations do collapse. These thresholds are strongly influenced by the feedbacks associated with the detrital energy pathway, as they coincide with instability in the availability of invertebrate prey. Nutrients from mortality and defecation throughout the 
community are recycled by detritivorous invertebrates in the model, and made available to small predatory fish, that in turn support larger predators. This concurs with numerous studies showing that energy subsidies from nutrient recycling allow for high fish biomass and shallower size spectra on coral reefs, than are expected in light of their relatively low primary productivity (Ackerman et al. 2004, Trebilco et al. 2013, Barneche et al. 2014). When heavy overfishing removes larger predators, nutrient recycling is reduced and the detrital pathway becomes unstable (Fig. 6). A concurrent release of smaller bodied predators from predation mortality allows them to increase in abundance, increasing competition for the less reliable invertebrate food source and rendering the predator population susceptible to collapse. Tipping points appear to occur beyond a relative fishing mortality of 0.4 , and are generally negatively correlated with reef refuge density (Fig. 3b).

Another notable conclusion of our study is the paucity of herbivores on reefs with low structural complexity. Given that benthic primary production is held constant across scenarios, the pattern can be attributed solely to refuge availability and predation mortality. We show that when refuge density is low, releasing herbivorous prey fish from predation by removing predators does not influence their abundance, even when fishing pressure is high. This interaction between refuge density and prey release could help to explain why studies have shown variable evidence for trophic cascades in coral reefs (Ruttenberg et al. 2011, Rizzari et al. 2015, Roff et al. 2016), since very few take structural complexity into account in their analyses. Considering the importance of grazing in the resilience and recovery of coral reefs (Mumby et al. 2007), our findings increase concern for reefs that have lost a large amount of structure. Without the capacity to support herbivores, these reefs are likely to be vulnerable to algal overgrowth and potential longterm phase shifts.

Our results offer several nuanced guidelines for prioritizing the designation of no-take reserves vs. fishing zones. Reserves placed on reefs that have lost a large amount of structure have variable value depending on the objective. If the objective is to support fisheries spillover, then the low biomass of most fishes offers limited ecological functioning and value. If the objective is biodiversity conservation then protection afforded to herbivorous fishes may facilitate rates of coral recovery and the reestablishment of structurally complex habitat (Jones et al. 2004, Mumby et al. 2016), but with several caveats. First, our results suggest that the high predation mortality of herbivorous fish in low complexity habitats may constrain the extent of their recovery in no-take reserves because predator biomass will increase, and prey have nowhere to hide. Whether the effects will be strong enough to impact coral recovery is not yet clear. In the Caribbean, where large-bodied parrotfish dominate herbivorous fish biomass, predation effects in successful reserves were estimated to reduce grazing levels by only $2-8 \%$ because many species achieved a sizeescape from predators (Mumby et al. 2006). On Pacific reefs, herbivore biomass is dominated by smaller-bodied fishes including acanthurids and smaller parrotfishes (Bellwood et al. 2004, Mumby et al. 2013a), and so there is greater scope for predation effects (Graham et al. 2003). Second, if herbivore biomass and diversity is already high in fished areas then protection within reserves may not confer any added benefits, and third, if the low habitat complexity is a result of critical damage from blast fishing, where recovery rates may exceed decades (Peter J. Mumby, personal observation), then it is unlikely that reserve designation will help.

Reefs of medium structural complexity appear to offer the highest fisheries productivity and may be appropriate locations for fishing. Reserve placement in such areas is not inadvisable since biomass is fairly high, but in light of our study, greater priority should be given to reefs of high complexity. High complexity reefs have the highest biomass which maximizes the potential for larval spillover (Harrison et al. 2012, Krueck et al. 2017), but importantly, they do not provide the highest fisheries productivity due to food limitation in larger bodied predators. Thus, reefs of high complexity are better suited to reserve functioning than fisheries functioning. This does not imply that fishing should not take place in high complexity habitats as they still offer significant fisheries benefits; rather, they might have lower weighting for fishing, all else being equal, and optimal catches may be achieved at reduced fishing effort. Interestingly, if fishing does indeed have a stronger negative effect on predators in high complexity habitats, then this may allow modest increases in herbivores which could reinforce the resilience of habitat quality when such areas were fished.

Of course, any practical decision requires additional context. First, decisions on where to fish involve factors including local governance arrangements and the costs of exploiting a location. Second, reserve designation must also consider questions of governance (Gill et al. 2017), connectivity (Krueck et al. 2017), and the broader set of conservation targets (Beger et al. 2015). Third, the complexity of a reef habitat is not fixed in time and will cycle through periods of disturbance and recovery (Done 1992, Aronson and Precht 1995, Wolff et al. 2016). Where reserves are being planned for the long term then a form of resilience assessment might be undertaken to determine patterns in the relative state of reefs among locations and prioritise accordingly (Obura and Grimsditch 2009, Maynard et al. 2010, Mumby et al. 2013b, Lam et al. 2017). An exception occurs where areas of lower or higher reef complexity are directly predictable on the basis of chronic environmental pressures. Examples here include the loss of complexity in areas of high wave exposure (Chollett and Mumby 2012) or elevated abundance of branching corals (and complexity) in areas with persistent shelter from storms, such as in the lee of atolls (Burke 1982). 


\section{Limitations and future avenues for research}

As is the case with any complex model of an ecosystem, there are necessary assumptions that the model makes. Firstly, we assume that refuges reduce the availability of fish to predation. In general this is valid, but on coral reefs many predators, for example moray eels have evolved specialized behaviors and morphologies that enable them to feed more effectively in complex habitats. Furthermore, the predation efficiency of some ambush predators may not be hindered by structural complexity (Almany 2004, Feeney et al. 2012), and the prevalence of such behaviors could dampen net negative effects of high refuge density on predator assemblages. Important future research questions include; (1) whether predators have variable growth rates, or body condition on reefs of varying complexity, (2) whether predatory species alter their foraging behavior in relation to refuge density and (3) whether refuge density positively correlates with predator foraging specializations.

In modeling the refuge effect of crevices on reefs we also made the assumption that each crevice was occupied by one individual that was of a similar size to the crevice, and competition occurred only between fish of the same size. In reality, larger crevices are often occupied by multiple small fish, competition varies based on species identity, and multiple fish use multiple refuges at different times depending on proximity and flee response (Menard et al. 2012). In this study, it is the lack of available small prey fish that drives predicted declines in predator productivity when refuge density is high. If small fish were able to take refuge not only in small crevices but also in larger crevices, this would further decrease their availability and exacerbate the negative effects of complexity on predator productivity, catch and sensitivity to overfishing. Further empirical studies are required to refine the function that relates refuge availability, population density and size structure to predation risk in complex habitats.

Another important behavior we do not explicitly capture is schooling (Magurran 1990) or aggregating in general, a strategy employed by a number of common reef fish species. Schooling may allow for higher abundances of fish than our models predict, both in complex habitats where they aggregate, or low complexity habitats where they are less reliant on crevices to reduce their vulnerability. Pertinent future research studies could ask; (1) whether species adopt or change schooling behaviors in response to changes in structural complexity, or (2) whether the prevalence of schooling species is related to the availability of refuges.

Resource limitation of predators in highly complex habitats may be mitigated in natural reef ecosystems by a number of factors. Firstly, there could be supplemental prey availability, owing to the immigration of individuals onto the reef. A number of predatory and herbivorous reef fish spend the early stages of their development in nursery habitats such as seagrass, mangroves and reef flats
(Dahlgren and Eggleston 2000, Kimirei et al. 2013), and studies have shown that reefs in closer proximity to nursery habitats have increased fish abundance (Mumby et al. 2004). Immigrants source their food outside of the reef system and thus provide an energy supplement to the food web when they migrate. They provide food to larger predators and also contribute to the input of detritus that underpins the detrital food chain. It is possible that the contribution of immigrants to food web dynamics could be enough to overcome theoretical resource bottlenecks for predators, and future studies could be designed to test this. In light of its potential however, the protection of reef nursery habitats and seascape connectivity should be prioritized, particularly on reefs that are exploited. Similarly, roaming or transient behaviors by predators, particularly between patches of high and low structural complexity could allow them to overcome food limitation on complex reefs (Hixon and Carr 1997). Furthermore, the contribution that such predators might make to local detrital inputs could support the detrital trophic pathway and create stability in complex habitats. Predators may, for example live in complex reef patches where they are themselves protected from predation, but forage in nearby patches with lower complexity where prey are more available. Here, our simulations represent closed systems and our predictions relate to relatively site-attached reef fishes but future work, both empirical and theoretical, could help us capture the effects of transient behavior and patch dynamics on reef fisheries productivity.

A number of other environmental factors that vary in space and time, and for which we did not parameterize our model could influence resource availability and primary productivity on reefs. These include: (1) planktonic primary production, (2) larval supply, (3) nutrient availability and benthic primary production and (4) detrital input and recycling dynamics, for example from transient predators, spawning aggregations or the breakdown of algae. However, the aim of this study was not to predict fish production in different reefs, but rather to explore the relative influences of structural complexity and fishing pressure on ecosystem dynamics and fish trophic guilds.

\section{Conclusions}

Owing to the potential for trophically constrained predators, we caution that healthy coral reefs may be more vulnerable to over-exploitation than we think. Furthermore, differences in the ways in which predators and herbivores respond to refuge availability and fishing pressure, indicate that they require different management strategies to promote persistence and productivity. Whilst predators may need more cautious management on complex reefs, herbivores are highly dependent on structural complexity, and its protection is likely to be vital to ensure ecosystem resilience. With this in mind, we suggest that reefs with persistently high structural complexity are sensible choices for the placement of 
marine protected areas because they support high fish biomass, have and good spillover potential but are not necessarily the most productive. Reefs with intermediate complexity are potentially good target locations for reef fisheries utilization, with all else being equal. For reefs whose structure is already heavily degraded, a novel management strategy could be continued predator fishing but herbivore protection (Rogers et al. 2015) to promote increased grazing and in turn, coral recruitment and habitat restoration. Finally, we caution researchers and managers not to under-estimate the value and importance of detritivores and nutrient-recyclers on coral reefs. Though they are often small, detritivores form the basis of a seemingly vital energy pathway on reefs. Improving our understanding of their dynamics and vulnerability is an important avenue for further research. Modeling studies like ours have limitations, but their value lies in their capacity to explore underlying system dynamics that we cannot see. In doing so they provide us with clues to help us prevent ecosystem decline, promote service provision and ensure the future functioning of coral reefs.

\section{ACKNOWLedgments}

This research was funded by the Capturing Coral Reef Ecosystem Services project supported by the World Bank, GEF and UQ. Additional funds were made available for the Caribbean data collection from the European Commission 7th Framework Programme (P7/2007-2013; Grant 244161).

\section{Literature Cited}

Abesamis, R., A. Green, G. Russ, and C. Jadloc. 2014. The intrinsic vulnerability to fishing of coral reef fishes and their differential recovery in fishery closures. Reviews in Fish Biology and Fisheries 24:1033-1063.

Ackerman, J. L., D. R. Bellwood, and J. H. Brown. 2004. The contribution of small individuals to density-body size relationships: Examination of energetic equivalence in reef fishes. Oecologia 139:568-571.

Almany, G. R. 2004. Differential effects of habitat complexity, predators and competitors on abundance of juvenile and adult coral reef fishes. Oecologia 141:105-113.

Alongi, D. M. (1989). Detritus in coral reef ecosystems: fluxes and fates. Sixth International Coral Reef Symposium. Volume 1. Pages 29-36. J. H. Choat, Townsville, Queensland, Australia.

Alvarez-Filip, L., N. K. Dulvy, J. A. Gill, I. Cote, and A. R. Watkinson. 2009. Flattening of Caribbean coral reefs: regionwide declines in architectural complexity. Philosophical Transactions of the Royal Society B: Biological Sciences 276:3019-3025.

Alvarez-Filip, L., J. A. Gill, and N. K. Dulvy. 2011. Complex reef architecture supports more small-bodied fishes and longer food chains on Caribbean reefs. Ecosphere 2:art118.

Aronson, R. B., and W. F. Precht. 1995. Landscape patterns of reef coral diversity: a test of the intermediate disturbance hypothesis. Journal of Experimental Marine Biology and Ecology 192:1-14.

Barbosa, P., and I. Castellanos (2005). Ecology of predator-prey interactions. Oxford Univ. Press, New York, New York and USA.

Barneche, D. R., M. Kulbicki, S. R. Floeter, A. M. Friedlander, J. Maina, and A. P. Allen. 2014. Scaling metabolism from individuals to reef-fish communities at broad spatial scales. Ecology Letters 17:1067-1076.

Beger, M., J. McGowan, E. A. Treml, A. L. Green, A. T. White, N. H. Wolff, C. J. Klein, P. J. Mumby, and H. P. Possingham. 2015. Integrating regional conservation priorities for multiple objectives into national policy. Nature Communications 6:8208.

Bejarano, S., P. J. Mumby, and I. Sotheran. 2010. Predicting structural complexity of reefs and fish abundance using acoustic remote sensing (RoxAnn). Marine Biology 158: 489-504.

Bellwood, D. R., T. P. Hughes, C. Folke, and M. Nystrom. 2004. Confronting the coral reef crisis. Nature 429:827-833.

Blanchard, J. L., R. Law, M. D. Castle, and S. Jennings. 2010. Coupled energy pathways and the resilience of size-structured food webs. Theoretical Ecology 4:289-300.

Blanchard, J. L., S. Jennings, R. Holmes, J. Harle, G. Merino, J. I. Allen, J. Holt, N. K. Dulvy, and M. Barange. 2012. Potential consequences of climate change for primary production and fish production in large marine ecosystems. Philosophical Transactions of the Royal Society B: Biological Sciences 367:2979-2989.

Bozec, Y.-M., L. Yakob, S. Bejarano, and P. J. Mumby. 2013. Reciprocal facilitation and non-linearity maintain habitat engineering on coral reefs. Oikos 122:428-440.

Burke, R. B. (1982). Reconnaissance study of the geomorphology and benthic communities of the outer barrier reef platform, Belize. Pages 509-526 in K. Rutzler, and I. G. Macintyre, editors. Smithsonian contributions to marine science 12. Smithsonian Institution, Washington, D.C.

Cardinale, B. J., D. S. Srivastava, J. Emmett Duffy, J. P. Wright, A. L. Downing, M. Sankaran, and C. Jouseau. 2006. Effects of biodiversity on the functioning of trophic groups and ecosystems. Nature 443:989-992.

Carpenter, K. E., and V. G. Springer. 2005. The center of the center of marine shore fish biodiversity: the Philippine Islands. Environmental Biology of Fishes 72:467-480.

Chase, J. M. 1999. Food web effects of prey size Refugia: variable interactions and alternative stable equilibria. American Naturalist 154:559-570.

Chase, J. M., P. A. Abrams, and J. P. Grover. 2002. The interaction between predation and competition: A review and synthesis. Ecology Letters 5:302-315.

Chollett, I., and P. J. Mumby. 2012. Predicting the distribution of Montastraea reefs using wave exposure. Coral Reefs 31:493-503.

Dahlgren, C. P., and D. B. Eggleston. 2000. Ecological processes underlying ontogentic habitat shifts in a coral reef fish. Ecology 81:2227-2240.

Depczynski, M., C. Fulton, M. Marnane, and D. Bellwood. 2007. Life history patterns shape energy allocation among fishes on coral reefs. Oecologia 153:111-120.

Done, T. J. 1992. Coral reef oceanography effects of tropical cyclone waves on ecological and geomorphological structures on the Great Barrier Reef. Continental Shelf Research 12:859-872.

Dulvy, N. K., R. P. Freckleton, and N. V. C. Polunin. $2004 a$. Coral reef cascades and the indirect effects of predator removal by exploitation. Ecology Letters 7:410-416.

Dulvy, N. K., N. V. C. Polunin, A. C. Mill, and N. A. J. Graham. 2004b. Size structural change in lightly exploited coral reef fish communities: evidence for weak indirect effects. Canadian Journal of Fisheries and Aquatic Sciences 61: 466-475.

Feary, D. A., G. R. Almany, M. I. McCormick, and G. P. Jones. 2007. Habitat choice, recruitment and the response of coral reef fishes to coral degradation. Oecologia 153:727-737. 
Feeney, W. E., O. M. Lönnstedt, Y. Bosiger, J. Martin, G. P. Jones, R. J. Rowe, and M. I. McCormick. 2012. High rate of prey consumption in a small predatory fish on coral reefs. Coral Reefs 31:909-918.

Friedlander, A. M., and J. D. Parrish. 1998. Habitat characteristics affecting fish assemblages on a Hawaiian coral reef. Journal of Experimental Marine Biology and Ecology 224:1-30.

Friedlander, A. M., E. K. Brown, P. L. Jokiel, W. R. Smith, and K. S. Rodgers. 2003. Effects of habitat, wave exposure, and marine protected area status on coral reef fish assemblages in the Hawaiian archipelago. Coral Reefs 22:291-305.

Friedlander, A. M., E. Brown, and M. E. Monaco. 2007. Defining reef fish habitat utilization patterns in Hawaii: comparisons between marine protected areas and areas open to fishing. Marine Ecology Progress Series 351:221-233.

Gill, D. A., et al. 2017. Capacity shortfalls hinder the performance of marine protected areas globally. Nature 543:665-669.

González-Olivares, E., and R. Ramos-Jiliberto. 2003. Dynamic consequences of prey refuges in a simple model system: more prey, fewer predators and enhanced stability. Ecological Modeling 166:135-146.

Graham, N. A. J., and K. L. Nash. 2012. The importance of structural complexity in coral reef ecosystems. Coral Reefs 32:315-326.

Graham, N. A. J., R. D. Evans, and G. R. Russ. 2003. The effects of marine reserve protection on the trophic relationships of reef fishes on the Great Barrier Reef. Environmental Conservation 30:200-208.

Gratwicke, B., and M. R. Speight. 2005. Effects of habitat complexity on Caribbean marine fish assemblages. Marine Ecology Progress Series 292:301-310.

Grigg, R. W. 1994. Effects of sewage discharge, fishing pressure and habitat complexity on coral ecosystems and reef fishes in Hawaii. Marine Ecology Progress Series 103:17-23.

Harborne, A. R., P. J. Mumby, and R. Ferrari. 2012. The effectiveness of different meso-scale rugosity metrics for predicting intra-habitat variation in coral-reef fish assemblages. Environmental Biology of Fishes 94:431-442.

Harrison, H. B., et al. 2012. Larval export from marine reserves and the recruitment benefit for fish and fisheries. Current Biology 22:1023-1028.

Hatcher, B. G. 1988. Coral reef primary productivity: A beggar's banquet. Trends in Ecology \& Evolution 3:106-111.

Hixon, M. A., and J. P. Beets. 1989. Shelter characteristics and Caribbean fish assemblages: experiments with artificial reefs. Bulletin of Marine Science 44:660-680.

Hixon, M. A., and J. P. Beets. 1993. Predation, prey refuges and the structure of coral reef fish assemblages. Ecological Monographs 63:77-101.

Hixon, M. A., and M. H. Carr. 1997. Synergistic pedation, density dependence, and population regulation in marine fish. Science 277:946-949.

Hixon, M. A., and B. A. Menge. 1991. Species diversity: Prey refuges modify the interactive effects of predation and competition. Theoretical Population Biology 39:178-200.

Jackson, J. B. C., et al. 2001. Historical overfishing and the recent collapse of coastal ecosystems. Science 293:629-637.

Jennings, S., and V. C. P. Nicholas. 1996. Impacts of fishing on tropical reef ecosystems. Ambio 25:44-49.

Jennings, S., S. P. R. Greenstreet, and J. D. Reynolds. 1999. Structural change in an exploited fish community: a consequence of differential fishing effects on species with contrasting life histories. Journal of Animal Ecology 68:617-627.

Jones, G. P., M. I. McCormick, M. Srinivasan, and J. V. Eagle. 2004. Coral decline threatens fish biodiversity in marine reserves. Proceedings of the National Academy of Sciences of the United States of America 101:8251-8253.
Karino, K., and A. Nakazono. 1993. Reproductive behavior of the territorial herbivore Stegastes nigricans (Pisces: Pomacentridae) in relation to colony formation. Journal of Ethology 11:99-110.

Kimirei, I. A., I. Nagelkerken, M. Trommelen, P. Blankers, N. van Hoytema, D. Hoeijmakers, C. M. Huijbers, Y. D. Mgaya, and A. L. Rypel. 2013. What drives ontogenetic niche shifts of fishes in coral reef ecosystems? Ecosystems 16:783-796.

Kramer, M. J., D. R. Bellwood, and O. Bellwood. 2014. Benthic crustacea on coral reefs: a quantitative survey. Marine Ecology Progress Series 511:105-116.

Krueck, N. C., G. N. Ahmadia, H. P. Possingham, C. Riginos, E. A. Treml, and P. J. Mumby. 2017. Marine reserve targets to sustain and rebuild unregulated fisheries. PLOS Biology 15: e2000537.

Lam, V. Y. Y., C. Doropoulos, and P. J. Mumby. 2017. The influence of resilience-based management on coral reef monitoring: A systematic review. PLoS ONE 12:e0172064.

Law, R., M. J. Plank, A. James, and J. L. Blanchard. 2009. Sizespectra dynamics from stochatic predation and growth of individuals. Ecology 90:802-811.

Law, R., M. J. Plank, and J. Kolding. 2012. On balanced exploitation of marine ecosystems: results from dynamic size spectra. ICES Journal of Marine Science 69:602-614.

Luckhurst, B. E., and K. Luckhurst. 1978. Analysis of the influence of substrate variables on coral reef fish communities. Marine Biology 49:317-323.

MacNeil, M. A., et al. 2015. Recovery potential of the world's coral reef fishes. Nature 520:341-344.

Magurran, A. E. 1990. The adaptive significance of schooling as an anti-predator defence in fish. Annales Zoologici Fennici 27:51-66.

Maynard, J. A., P. A. Marshall, J. E. Johnson, and S. Harman. 2010. Building resilience into practical conservation: identifying local management responses to global climate change in the southern Great Barrier Reef. Coral Reefs 29:381-391.

McClanahan, T. R., N. A. J. Graham, M. A. MacNeil, N. A. Muthiga, J. E. Cinner, J. H. Bruggemann, and S. K. Wilson. 2011. Critical thresholds and tangible targets for ecosystembased management of coral reef fisheries. Proceedings of the National Academy of Sciences of the United States of America 108:17230-17233.

McNair, J. N. 1986. The effects of refuges on predator-prey interactions: A reconsideration. Theoretical Population Biology 29:38-63.

Menard, A., K. Turgeon, D. G. Roche, S. A. Binning, and D. L. Kramer. 2012. Shelters and their use by fishes on fringing coral reefs. PLoS ONE 7:e38450.

Mora, C., et al. 2011. Global human footprint on the linkage between biodiversity and ecosystem functioning in reef fishes. PLoS Biology 9:e1000606.

Mumby, P. J., and C. C. C. Wabnitz. 2002. Spatial patterns of aggression, territory size, and harem size in five sympatric Caribbean parrotfish species. Environmental Biology of Fishes 63:265-279.

Mumby, P. J., et al. 2004. Mangroves enhance the biomass of coral reef fish communities in the Caribbean. Nature 427:533-536.

Mumby, P. J., et al. 2006. Fishing, trophic cascades, and the process of grazing on coral reefs. Science 311:98-101.

Mumby, P. J., A. Hastings, and H. J. Edwards. 2007. Thresholds and the resilience of Caribbean coral reefs. Nature 450: 98-101.

Mumby, P. J., S. Bejarano, Y. Golbuu, R. S. Steneck, S. N. Arnold, R. Woesik, and A. M. Friedlander. 2013a. Empirical relationships among resilience indicators on Micronesian reefs. Coral Reefs 32:213-226. 
Mumby, P. J., N. H. Wolff, Y.-M. Bozec, I. Chollett, and P. Halloran. 2013b. Operationalizing the resilience of coral reefs in an era of climate change. Conservation Letters 1-12.

Mumby, P. J., R. S. Steneck, M. Adjeroud, and S. N. Arnold. 2016. High resilience masks underlying sensitivity to algal phase shifts of Pacific coral reefs. Oikos 125:644-655.

Myers, R. A., and B. Worm. 2005. Extinction, survival or recovery of large predatory fishes. Philosophical Transactions of the Royal Society of London B: Biological Sciences 360: $13-20$.

Newman, S. P., E. H. Meesters, C. S. Dryden, S. M. Williams, C. Sanchez, P. J. Mumby, and N. V. C. Polunin. 2015. Reef flattening effects on total richness and species responses in the Caribbean. Journal of Animal Ecology 84:1678-1689.

Newton, K., I. M. Côté, G. M. Pilling, S. Jennings, and N. K. Dulvy. 2007. Current and future sustainability of island coral reef fisheries. Current Biology 17:655-658.

Obura, D. O., and G. Grimsditch (2009). Resilience assessment of coral reefs - assessment protocol for coral reefs, focusing on coral bleaching and thermal stress. Page 71. IUCN, Gland, Switzerland.

O'Farrell, S., A. R. Harborne, Y. M. Bozec, B. E. Luckhurst, and P. J. Mumby. 2015. Protection of functionally important parrotfishes increases their biomass but fails to deliver enhanced recruitment. Marine Ecology Progress Series 522:245-254.

Pauly, D. 1998. Fishing down marine food webs. Science 279:860-863.

Plank, M. J., and R. Law. 2011. Ecological drivers of stability and instability in marine ecosystems. Theoretical Ecology 5:465-480.

Risk, M. J. 1972. Fish diversity on a coral reef in the Virgin Islands. Atoll Research Bulletin 153:1-6.

Rizzari, J. R., B. J. Bergseth, and A. J. Frisch. 2015. Impact of conservation areas on trophic interactions between apex predators and herbivores on coral reefs. Conservation Biology 29:418-429.

Rodwell, L. D., E. B. Barbier, C. M. Roberts, and T. R. McClanahan. 2003. The importance of habitat quality for marine reserve - fishery linkages. Canadian Journal of Fisheries and Aquatic Sciences 60:171-181.

Roff, G., C. C. C. Wabnitz, A. R. Harborne, and P. J. Mumby. 2013. Macroalgal associations of motile epifaunal invertebrate communities on coral reefs. Marine Ecology 34: $409-419$.

Roff, G., C. Doropoulos, A. Rogers, Y.-M. Bozec, N. C. Krueck, E. Aurellado, M. Priest, C. Birrell, and P. J. Mumby. 2016. The ecological role of sharks on coral reefs. Trends in Ecology \& Evolution 31:395-407.
Rogers, A., J. L. Blanchard, and P. J. Mumby. 2014. Vulnerability of coral reef fisheries to a loss of structural complexity. Current Biology 24:1000-1005.

Rogers, A., et al. 2015. Anticipative management for coral reef ecosystem services in the 21st century. Global Change Biology 21:504-514.

Ruttenberg, B. I., S. L. Hamilton, S. M. Walsh, M. K. Donovan, A. Friedlander, E. DeMartini, E. Sala, and S. A. Sandin. 2011. Predator-induced demographic shifts in coral reef fish assemblages. PLoS ONE 6:e21062.

Sih, A. 1987. Prey refuges and predator-prey stability. Theoretical Population Biology 31:1-12.

Sih, A., P. Crowley, M. McPeek, J. Petranka, and K. Strohmeier. 1985. Predation, competition, and prey communities: A review of field experiments. Annual Review of Ecology and Systematics 16:269-311

terHorst, C., and P. Munguia. 2008. Measuring ecosystem function: consequences arising from variation in biomassproductivity relationships. Community Ecology 9:39-44.

Trebilco, R., J. K. Baum, A. K. Salomon, and N. K. Dulvy. 2013. Ecosystem ecology: size-based constraints on the pyramids of life. Trends in Ecology \& Evolution 28:423-431.

Werner, E. E., and J. F. Gilliam. 1984. The ontogenetic niche and species interactions in size-structured populations. Annual Review of Ecology and Systematics 15:393-425.

Wilson, S. K., R. Fisher, M. S. Pratchett, N. A. J. Graham, N. K. Dulvy, R. A. Turner, A. Cakacaka, N. V. C. Polunin, and S. P. Rushton. 2008. Exploitation and habitat degradation as agents of change within coral reef fish communities. Global Change Biology 14:2796-2809.

Wilson, S. K., R. Fisher, M. S. Pratchett, N. A. J. Graham, N. K. Dulvy, R. A. Turner, A. Cakacaka, and N. V. C. Polunin. 2010. Habitat degradation and fishing effects on the size structure of coral reef fish communities. Ecological Applications 20:442-451.

Wilson, S. K., R. C. Babcock, R. Fisher, T. H. Holmes, J. A. Y. Moore, and D. P. Thomson. 2012. Relative and combined effects of habitat and fishing on reef fish communities across a limited fishing gradient at Ningaloo. Marine Environmental Research 81:1-11.

Wolff, N. H., A. Wong, R. Vitolo, K. Stolberg, K. R. N. Anthony, and P. J. Mumby. 2016. Temporal clustering of tropical cyclones on the Great Barrier Reef and its ecological importance. Coral Reefs 35:613-623.

Woodworth-Jefcoats, P. A., J. J. Polovina, J. P. Dunne, and J. L. Blanchard. 2013. Ecosystem size structure response to $21 \mathrm{st}$ century climate projection: large fish abundance decreases in the central North Pacific and increases in the California Current. Global Change Biology 19:724-733.

\section{SUPPORTING INFORMATION}

Additional supporting information may be found in the online version of this article at http://onlinelibrary.wiley.com/doi/10. 1002/ecy.2103/suppinfo

\section{Data Availability}

